\title{
Esperanzas en Centroamérica ¿Estamos ante un ciclo que abre una nueva oportunidad de vivir?
}

${ }^{1}$ Francisco Bautista Lara

\author{
Recibido: 23 de julio de 2012/Aprobado: 27 de julio de 2012.
}

\section{1 orque Dios no hizo la muerte, y no le gusta que se pierdan los vivos. Él creó todas las cosas para que existan... La tierra no está sometida a la muerte, pues el orden de la justicia está más allá de la muerte".} Libro de la Sabiduría, 1,13-15.

Las inseguridades, crisis, riesgos y esperanzas en Centroamérica han cambiado desde los tiempos de la Declaración de la Independencia de España en 1821, pasando por las revueltas entre conservadores y liberales, las intervenciones, las dictaduras, los golpes de estado, las revoluciones, los gobiernos autoritarios y los movimientos guerrilleros, la represión política, las violaciones a los derechos humanos, los acuerdos de paz y las desmovilizaciones de los grupos armados llegando en esta época de crisis del capitalismo mundial, globalización, información y rápidos cambios en todos los ámbitos, a las nuevas amenazas por la delincuencia local y transnacional, el narcotráfico, las pandillas, la corrupción pública y privada, los conflictos fronterizos, los acuerdos de libre comercio, los desastres naturales, el deterioro medioambiental y la desconfianza social e institucional. Han sido constantes la desigualdad, la pobreza, los desequilibrios socioeconómicosy la fragilidad del sistema político. La región tiene condiciones dispares de desarrollo e inseguridad, continúan vigentes las raíces de los viejosy nuevos conflictos. La inseguridad por la delincuencia se suma al resto de inseguridades cuyas percepciones $\mathrm{y}$ riesgos objetivos no son homogéneos en el

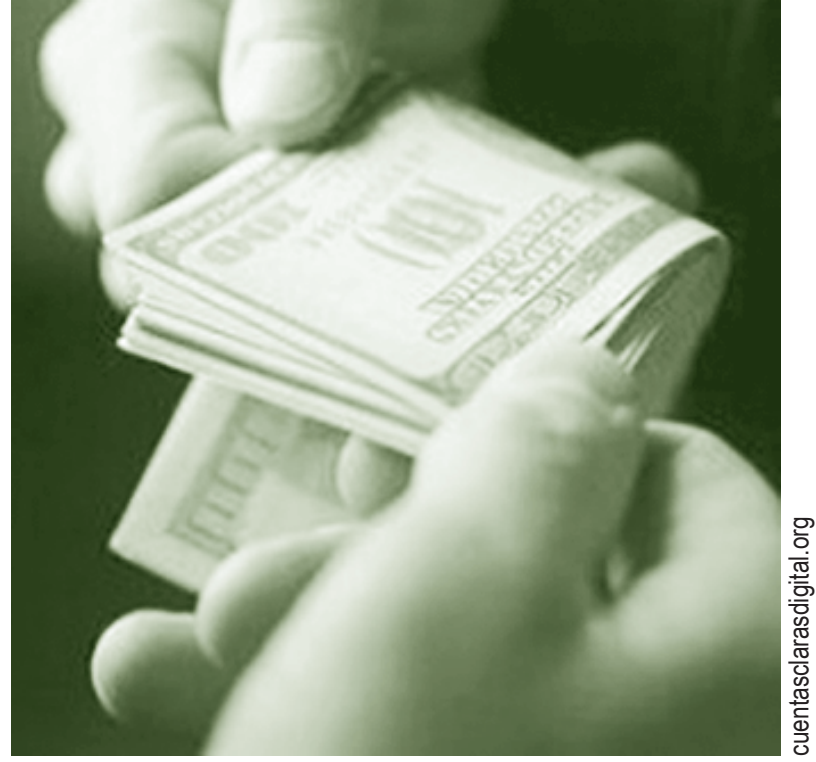

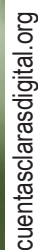

\section{RESUMEN}

El experto en seguridad Francisco Bautista Lara, analiza las tendencias de la violencia delictiva en la región centroamericana, identificando últimamente señales positivas, pero afirmando que "la frecuencia de delitos graves cambia de manera sostenible y no ocasional solo cuando se modifican las causas y circunstancias que la originan".

Palabras clave: Violencia, seguridad, equidad, acuerdo social.

\section{ABSTRACT}

Francisco Bautista Lara, security expert, analyzes trends in violent crime in Central America, identifying positive signs, but stating that "the frequency of serious crimes changes of sustainable way and not just occasionally when changing the causes and circumstances that originated it".

Keywords: Violence, security, equity, social agreement.

1 Comisionado General (R), Especialista en Seguridad Ciudadana, escritor, Managua, Nicaragua. 17-072012. www.franciscobautista.con 


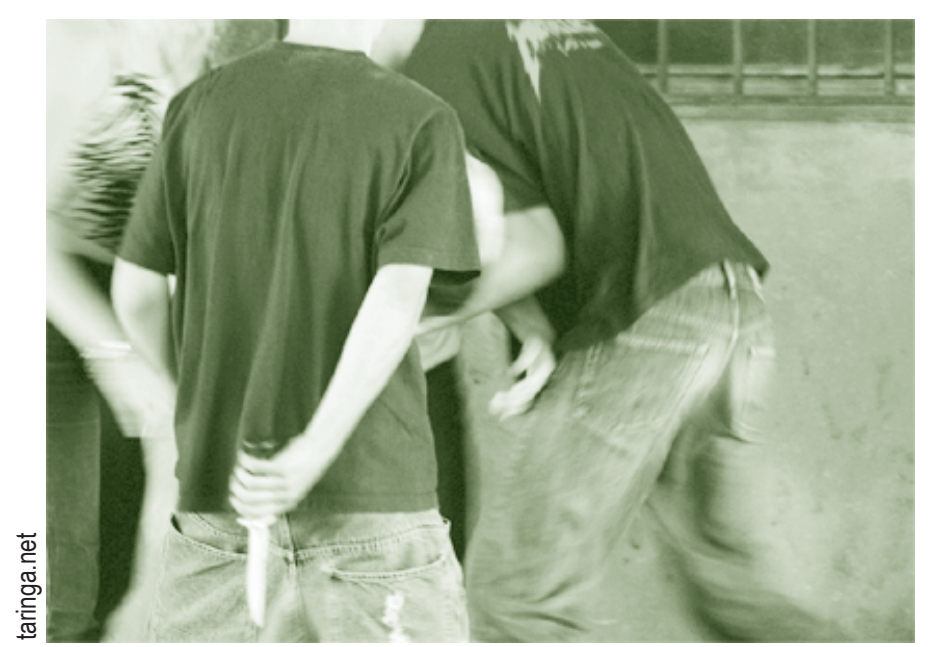

territorio, entre los países nientre hombres y mujeres. Los riesgos y oportunidades cambian entre generaciones, por el origen étnico y la posición social y económica.

Finalizado el conflicto armado, firmada la paz (ElSalvador 1992, Guatemala 1996, Nicaragua 1990) y desmovilizados los grupos armados (Nicaragua 1990 -2001), la violencia por ese motivo concluyó. Quedaron en evidencia otras formas, algunas como consecuencia de los estragos causados por la confrontación bélica, por la exclusión, la migración y deportación, el conflicto de la convivencia y las nuevas amenazas externas que encuentran en las condiciones internas de fragilidad y desintegración, un favorable escenario para su desarrollo.

El periodo comprendido entre 2004 y 2010/2011 representó para Centroamérica un creciente deterioro en la seguridad ciudadana medida por la cantidad de muertes por la violencia delictiva: entre 16 y 19 mil víctimas anuales. El 2010 cierra con la mayor cantidad de consecuencias fatales por la delincuencia al alcanzar 18,985. La situación más crítica en Guatemala con (34\%), seguido de Honduras (33\%) y El Salvador (21\%). Los países del sur de la Región no estuvieron ajenos a esa tendencia aunque con una situación menos grave: Nicaragua $(4.4 \%)$, Panamá (3.9\%), Costa Rica (2.9\%) y Belice $(0.7 \%)$.

El delito de mayor preocupación por sus consecuencias es el homicidio agrupando en esa categoría las formas delictivas quellevana la muerte de una persona (asesinato, homicidio, homicidio imprudente, feminicidio, parricidio) en correspondencia a las distintas legislaciones penales. Es utilizado con frecuencia para medir el grado de violencia delictiva porque tiene muy baja cifra oscura. Hay tres situaciones que podrían esconder un porcentaje de muertes delictivas no conocidas: i) la cantidad de desaparecidos, ¿Cuántas personas desaparecen y porqué? ii) las lesiones graves o gravísimas con peligro de muerte y iii) las aparentemente provocadas por accidente de tránsito, suicidio y otras presuntamente "naturales". En estos casos es probable que se produzca la muerte de una persona, o que el "accidente" esconda la acción delictiva deliberada. Muchas veces la información oficial no recoge el problema. En Nicaragua, el registro de homicidios lo proporciona unilateralmente la Policía. En El Salvador y Costa Rica, es derivado de la conciliación entre la Policía, Fiscalía e Instituto Forense. Es recomendable, según se indicó en "Seguridad Ciudadana 1998-2010, Nicaragua: Riesgos, Retos y Oportunidades" (PNUD, agosto 2011) que los datos de los principales delitos, particularmente homicidios, sean construidos interinstitucional para disponer de información consistente.

La tasa mundial de homicidios se estima en $8 \times 10$ mil habitantes. En 2010 Centroamérica registró 40 x 100 mil habitantes, estando por encima Honduras, El Salvador y Guatemala, y por debajo: Panamá, Nicaragua y Costa Rica. Los países de la Región desafortunadamente muestran tasas superiores a 10, límite encima del cual la Organización Mundial de la Salud considera es un "problema epidémico".

HOMICIDIOS 2010 EN CENTROAMERICA

\begin{tabular}{|l|c|c|c|c|c|c|c|l|}
\hline País & Guatemala & Belice & Honduras & El Salvador & Nicaragua & Costa Rica & Panamá & Total \\
\hline Cantidad & 6502 & 132 & 6236 & 4004 & 826 & 547 & 738 & 18,985 \\
\hline$\%$ & 34 & 0.7 & 33 & 21 & 4.4 & 2.9 & 3.9 & $100 \%$ \\
\hline
\end{tabular}

Diversas fuentes 
Esa lamentable tendencia fue persistente en Centroamérica. Incluso Costa Rica y Panamá que tuvieron tasas de homicidio muy bajas en décadas anteriores (1990 - 2004: entre 5 y $8 \times 100$ mil habitantes), subieron a niveles que sorprendieron a sus ciudadanos. Panamá llegó en 2009 a 27 homicidios x 100 mil habitantes y Costa Rica, aunque continuó siendo la menor de la Región, llegó a 11.5 .

La tasa de homicidios que en Nicaragua tuvo el menor nivel de los últimos veinte años entre 2000-2002 (10 homicidios x 100 mil habitantes), desde 2003 comenzó a incrementarse hasta alcanzar $14 \times 100$ mil habitantes en 2010, la mayor desde 1997 cuando todavía existían remanentes de los alzados en armas que asolaron parte del territorio nacional provocando emboscadas, secuestros y asesinatos múltiples.

Según diversos estudios de percepción social, cerca de dos tercios de los habitantes de Guatemala, Honduras y El Salvador identifican como el principal problema del país la inseguridad y en segundo lugar los de naturaleza socioeconómica (desempleo, precios de los productos de consumo básico y otras necesidades sociales). En Nicaragua dos tercios de la población identifican como su principal preocupación los problemas de naturaleza socioeconómica y solo la tercera parte la inseguridad.

\begin{abstract}
Afortunadamente un fenómeno alentador que esperamos sea sostenible ha comenzado a manifestarse. En el año 2011 con respecto al 2010, Guatemala (-7.4\%) Costa Rica (-11\%) y Nicaragua (-7\%) reportaron, según sus registros oficiales, reducción de la tasa de homicidios y El Salvador, a partir de marzo de 2012 muestra una sorprendente baja en la frecuencia diaria de muertes a partir de la tregua asumida desde la cárcel entre los líderes de las dos grandes pandillas delictivas: la Mara Salvatrucha y la Mara 18. Panamá redujo ligeramente en $3.5 \%$ pero Honduras continúa presentando una violencia creciente siendo junto a Guatemala (a pesar de la baja de los homicidios), los eslabones más frágiles de la inseguridad ciudadana en la Región.
\end{abstract}

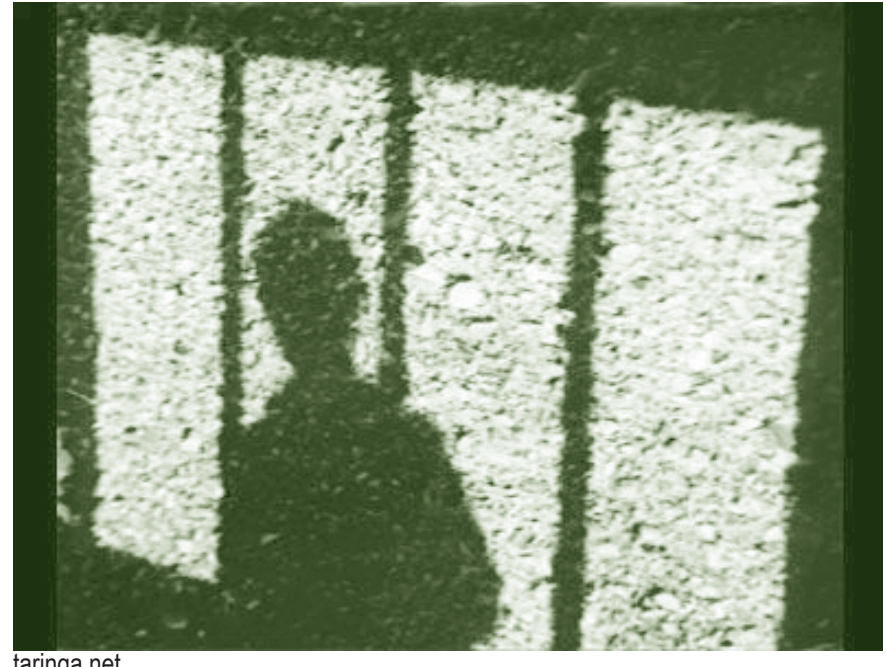

taringa.net

\section{GUATEMALA: MENOS HOMICIDIOS PERO} MAYOR VIOLENCIA. Aunque tiene la mayor cantidad absoluta de homicidios de la región; con respecto a su población (13.8 millones de habitantes, 30.6\% de C.A.), es la tercera, por debajo de Honduras y El Salvador. Presenta gran fragilidad y vulnerabilidad institucional que le limita actuar contra las manifestaciones del crimen organizado nacional y transnacional. Debido a la alta impunidad se firmó en 2006 un acuerdo entre el Gobierno y la ONU para instalar la CICIG (Comisión Internacional contra la Impunidad en Guatemala).

Aunque la tasa de homicidios bajó en 2010 y 2011 con respecto al año anterior, pasando de 46 homicidios por 100 mil habitantes en 2009 a 38.6 en 2011, durante el último año, se evidencia la organización y crueldad de las acciones criminales, incluyendo la masacre de 27 campesinos en el Petén y el asesinato del canta autor argentino Facundo Cabral que reveló una red delictiva organizada en Centroamérica vinculando a personas de nacionalidad mexicana, guatemalteca, colombiana, nicaragüense y costarricense.

En 2011 hay 7.4\% menos muertes que en 2010, sin embargo la acción de los Zetas y el sicariato aumentan, estimándose que en el 90\% de los hechos utilizan armas de fuego. Lo bueno es que durante estos últimos dos años, hay quinientas víctimas menos anualmente.

NICARAGUA: MENOS HOMICIDIOS, MÁS MUERTES. La tasa de homicidios en Nicaragua al concluir 2011 fue de 12.9 x 100 mil habitantes, observó 
un descenso con respecto al 2010 cuando llegó a 14.2.Afortunadamente en 2011 la Policía conoció menos homicidios: 761, es decir 7\% menos que el año anterior (2010) que alcanzó la sorprendente cantidad de 826 víctimas, la mayor desde 1992 (840). Esta reducción, se vio afectada por el incremento significativo de muertes por accidentes de tránsito y suicidios. El balance de muertes violentas provocadas en Nicaragua entre 2010 y 2011 observó un ligero incremento al pasar de 1,598 en 2010 a 1,609 en 2011, es decir, 11 personas adicionales truncaron sus vidas. En Managua ocurren el 30\% de las muertes violentas del país.

Las víctimas por accidentes de tránsito pasaron de 571 en 2010 a 613 el año pasado, un incremento de $7 \%$. Sorprende que los suicidios subieron de 174 a 201, ¿Por qué ese aumento? ¿Qué factores personales, familiares y sociales truncaron las vidas de personas mayoritariamente entre 16 y 40 años? Tenemos que analizar dicha situación desde la sociedad y sus instituciones. Hay reducción de la cantidad de homicidios sin embargo hay más muertes violentas provocadas. En 2011 el 47\% fueron por homicidios (52\% en 2010), el $38 \%$ por accidentes de tránsito ( $36 \%$ en 2010), pregunto: ¿habrán sido todos realmente accidentes de tránsito? ¿Cuántos fueron encontrados atropellados en la calle donde el vehículo se fugó premeditadamente porque hubo intención?, y el $14.6 \%$ se registraron como suicidios (12.6\% en 2010), ¿pudo existir detrás una muerte intencional?

La estabilidad macroeconómica y los numerosos programas sociales impulsados por el gobierno desde

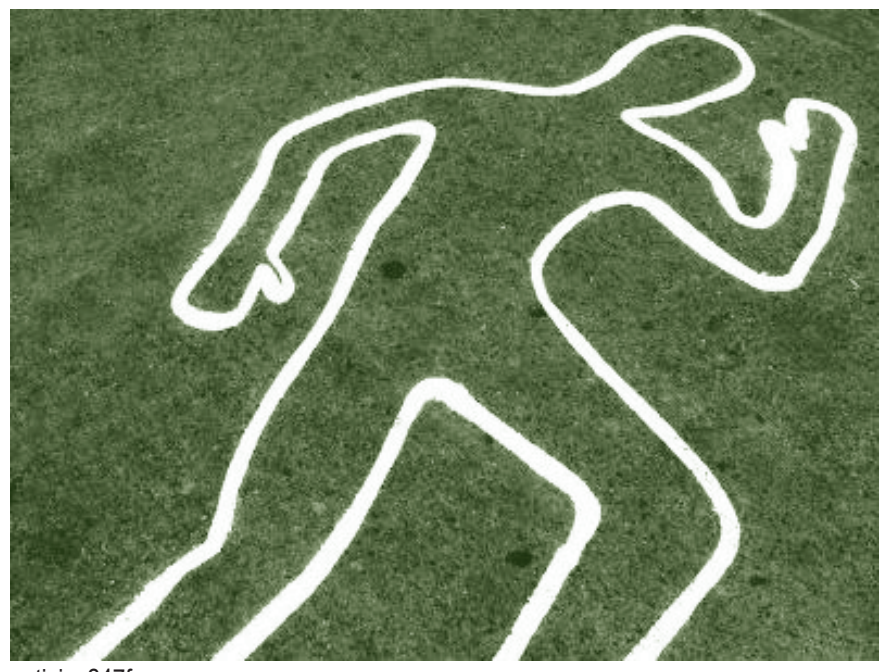

noticias $247 \mathrm{fm} . \mathrm{com}$
2006 que benefician a grupos vulnerables y contribuyen en reducir la pobreza, pueden mejorar sosteniblemente la seguridad ciudadana siempre y cuando fortalezcan la equidad y la institucionalidad. El $74.1 \%$ de las personas consideran que el país mejoró y el 33\% que también la económica familiar (M y R Consultores, julio 2012). Ello podrá reflejarse en la reducción de los delitos graves, principalmente el homicidio y el robo con fuerza e intimidación en calles y casas de habitación que son la preocupación social común.

MUERTES VIOLENTAS, NICARAGUA 2005 - 2011

\begin{tabular}{|c|c|c|c|c|c|}
\hline Año & homicidios & $\begin{array}{c}\text { P/ } \\
\text { accidentes }\end{array}$ & suicidios & total & $\begin{array}{c}\text { lesiones } \\
\text { graves }\end{array}$ \\
\hline 2005 & 729 & 472 & 173 & $\mathbf{1 3 7 4}$ & $\mathrm{x}$ \\
\hline 2006 & 722 & 472 & 217 & $\mathbf{1 4 1 1}$ & $\mathrm{x}$ \\
\hline 2007 & 714 & 522 & 143 & $\mathbf{1 3 7 9}$ & $\mathrm{x}$ \\
\hline 2008 & 736 & 514 & 121 & $\mathbf{1 3 7 1}$ & $\mathrm{x}$ \\
\hline 2009 & 802 & 601 & 174 & $\mathbf{1 5 7 7}$ & $\mathrm{x}$ \\
\hline 2010 & 826 & 571 & 201 & $\mathbf{1 5 9 8}$ & 2412 \\
\hline 2011 & 761 & 613 & 235 & $\mathbf{1 6 0 9}$ & 2484 \\
\hline total & $\mathbf{5 2 9 0}$ & $\mathbf{3 7 6 5}$ & $\mathbf{1 2 6 4}$ & $\mathbf{1 0 3 1 9}$ & \\
\hline media & 756 & 538 & 180 & $\mathbf{1 4 7 4}$ & \\
\hline
\end{tabular}

Fuente: Policía de Nicaragua

\section{HOMICIDIOS- NICARAGUA: TASA X $100 \mathrm{MIL}$ HABITANTES Y FRECUENCIA DIARIA}

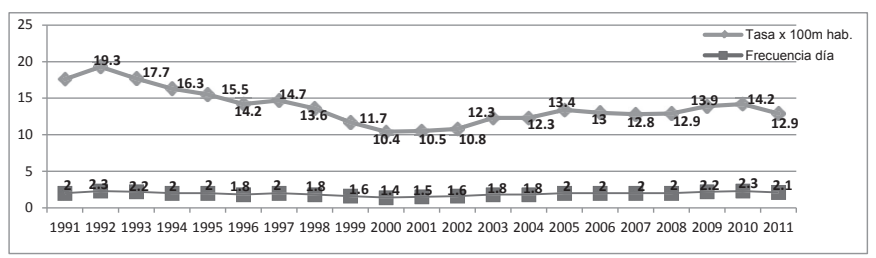

EL SALVADOR: ACUERDO ENTRE PANDILLAS. En 2003 la tasa era de 36, subió hasta 69 en 2011 con algunas disminuciones temporales. Inició enero y febrero del 2012 con los mismos resultados que provocaron 4,354víctimas en 2011. La tendencia de incremento de la violencia ha sido persistente hasta observar un brusco descenso en marzo de 2012 por una acción al margen del Gobierno aunque facilitada por las autoridades. El obispo castrense Fabio Colindres y el ex guerrillero Raúl Mijango, negociaron desde la cárcel de máxima seguridad, un acuerdo de tregua entre líderes de las pandillas Mara 18 y Mara 
Salvatrucha para cesar los asesinatos entre ellas. Aunque el anuncio fue el 20 de marzo, comenzó a cumplirse por los casi sesenta mil pandilleros de ambas organizaciones delictivas unos días antes de 12 de marzo, fecha de las elecciones municipales y legislativas. Lo solicitado por los cincuenta jefes mareros en prisión fue que mejoraran las condiciones de reclusión y les distribuyeran en cárceles comunes. Los mediadores gestionaron para que los presos fueran trasladados a otros penales y los grupos delictivos demostraron su capacidad de reducir los 14 homicidios diarios ocurridos en febrero, a 5 desde abril 2012. Si todo sigue así, 2012 concluirá con dos mil víctimas menos y la tasa de homicidios x 100 mil habitantes pasará de 69 a 28, debajo de Guatemala, Honduras y Belice, por arriba de Panamá, Nicaragua y C. Rica. El Salvador cambiará del primero al cuarto lugar en este indicador de inseguridad.

Mientras el Obispo señala que ha sido "un hecho providencial, un milagro", otros sectores opinan que es un acontecimiento que demuestra la incapacidad estatal ante el viejo problema que aqueja a la sociedad salvadoreña, incluso algunos especulan que "existen otras concesiones no conocidas", que se actúa temerariamente reconociendo a estos grupos delictivos un "poder" que en cualquier momento, después de la tregua, va a generar peores consecuencias. El resultado evidente es que la frecuencia diaria de homicidios pasó sorprendentemente de un día para otro, de 14 a 5, significa que nueve (9) de los casos ocurridos diariamente estaban relacionados al conflicto entre pandillas. Los cinco (5) que siguen ocurriendo, se vinculan a: conflictos de convivencia cotidiana (3), uno (1) a las pandillas y (1) a otras formas del crimen organizado.

Los líderes de la Mara Salvatrucha MS-13 y 18 presentaron (12/7/2012) al secretario general de la OEA, José Miguel Insulza en su visita al Centro Penal la Esperanza, la propuesta de entregar parte de sus armas como gesto de buena voluntad de la tregua entre pandillas. Carlos Ernesto Mojica, alias "El Viejo Lin" líder de la 18, acompañado de Carlos Siberio, de la Salvatrucha, dijo que ambas pandillas acordaron la paz con el "simbólico desarme parcial de nuestras estructuras". Al día siguiente fueron reunidas 70 armas de fuego ante la presencia de Insulza y el Obispo Colindres. Mojica agregó que en respuesta a la petición pública del presidente Mauricio Funes para cesar todo tipo de violencia contra las mujeres, "hemos girado instrucciones para contribuir a

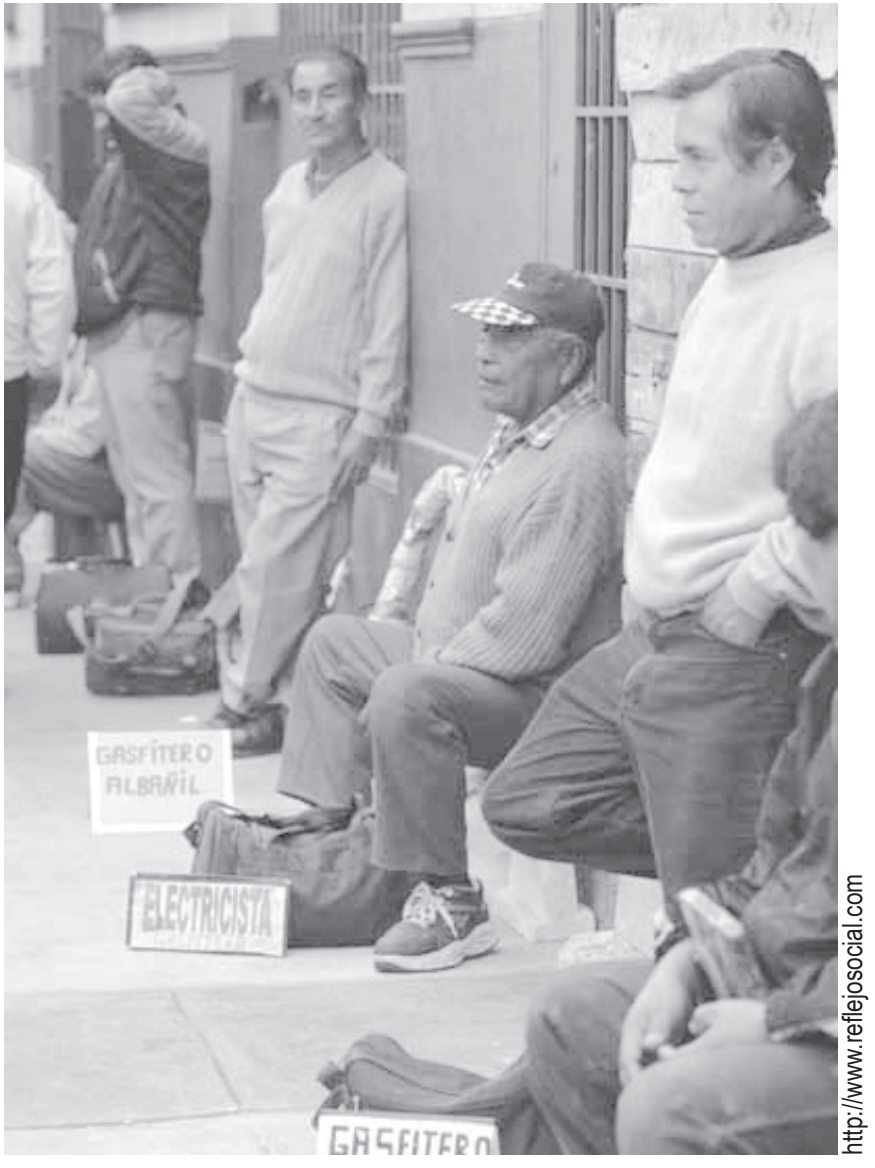

ese llamado". Los líderes pandilleros presentaron un documento en el que expresaron su posición en torno a la tregua y declararon como "zonas de paz" los centros escolares, anunciando que no reclutarán forzosamente a nuevos integrantes para evitar más violencia.

La reducción repentina de las muertes en El Salvador no obedeció a la acción preventiva o coercitiva del Estado sino a un factor extraordinario: la negociación a través de dos actores externos a las instituciones públicas, un representante de la Iglesia Católica y otro proveniente de organizaciones no gubernamentales. Sobre el "frágil acuerdo", surge la pregunta ¿qué tan sostenible es? Se requiere promover un audaz programa de reinserción, reducir la exclusión y ofrecer oportunidad de desarrollo para que los jóvenes no se incorporen a las pandillas y encuentren vías distintas para solucionar sus conflictos y necesidades de pertenencia. Queda demostrado que las medidas de mano dura desarrolladas por los gobiernos salvadoreños fracasaron, está por verse si el país aprovechará la nueva oportunidad para la vida con soluciones sostenibles. 


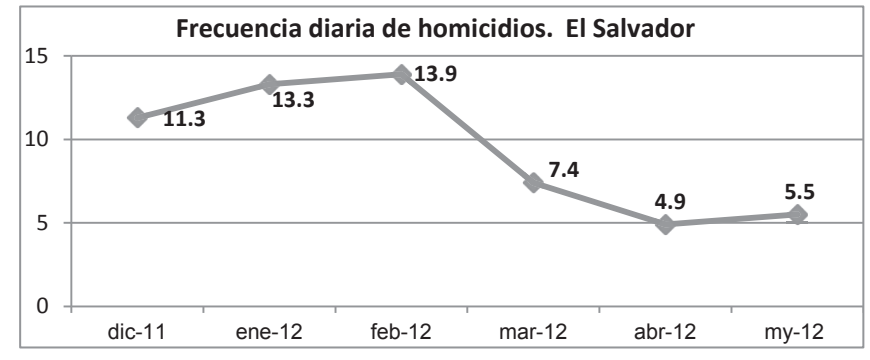

COSTA RICA: BAJAN HOMICIDIOS Y AUMENTAN NICARAGUENSES VICTIMAS. Según el Órgano Judicial de Costa Rica (31/5/2012), por primera vez desde 2005, el país observó (2011) reducción de la tasa de homicidios, ubicándose como el único de C.A. con resultados cercanos a 10 homicidios por 100 mil hab.: 10.3, bajaron de 527 víctimas (2010) a 474, una reducción del 11\% (53 menos). En 2010 llegaron al nivel más alto: $11.5 \times 100$ mil hab.

De conformidad con informes oficiales, el robo es la causa principal de los homicidios dolosos. En 2011, fueron identificados 17 por sicariato, 40 ocurrieron en 2010. Estaban vinculados a riñas por narcotráfico, rivalidades entre bandas y conflictos territoriales por la venta de estupefacientes 51 homicidios. En 5\% de los casos (23) se relacionaron como autores a 44 menores de edad. De las 474 víctimas, 378 (80\%) eran costarricenses, $55(12 \%)$ nicaragüenses (hace diez años no llegaban a 20) y $14(3 \%)$ colombianos (hace diez años no excedían de 2). En el $63 \%$ de los casos utilizaron armas de fuego. El $59 \%$ de los homicidios se registraron en San José (36\%) y Limón (23\%) en el Caribe costarricense. La justicia penal costarricense resolvió el $89 \%$ de los casos; fueron imputados 423 personas ante las autoridades respectivas. El $83 \%$ de los acusados eran costarricenses y $13 \%$ nicaragüenses (se duplicó en la década).

Según el censo poblacional de Costa Rica, en el 2000 había 226,374 nicaragüenses (6\% de la población), representaban el $76 \%$ de los migrantes. El Censo Nacional de Población y Vivienda (C. Rica, 2011) registró 287,766 nicaragüenses (6.7\% de la población), el 75\% de los migrantes que allí residen. Durante once años la población de nicas se incrementó en $27 \%$. El aumento de las víctimas e imputados por homicidios en el periodo fue mayor que el incremento de la población procedente de Nicaragua (al menos según censos oficiales). ¿Es posible que exista una alta población de inmigrantes nicaragüenses no censados por su situación ilegal? Partiendo que el comportamiento del ilegal no cambió entre los dos censos nacionales, es evidente que se duplicó el riesgo de un nicaragüense de ser víctima de homicidio en Costa Rica, siendo mayor que en Nicaragua y casi el doble con respecto a los costarricenses en general en ese país. La tasa de homicidios de nicaragüenses en 2011 fue 19 x 100 mil habitantes, y el de los costarricense 10 .

Tasa homicidios x 100 mil habitantes: Nicaragua - Costa Rica

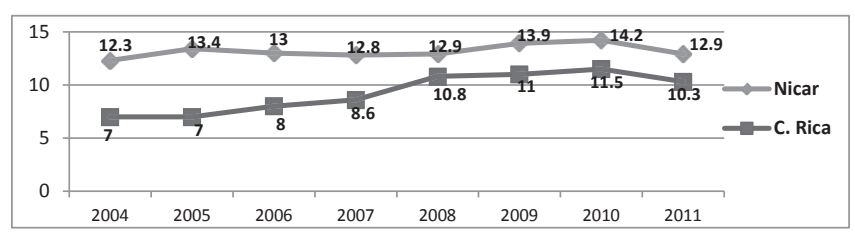

Frecuencia diaria anual homicidios:

El Salvador - Nicaragua - C. Rica

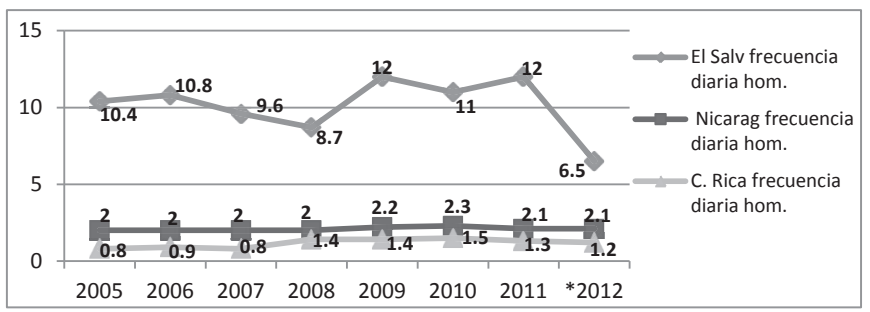

" $\mathrm{O}$ h crimen, cuantas libertades se cometen en tu nombre!"

Viva mi fama (1988), Carlos Fuentes (1928-2012).

La violencia delictiva agota irremediablemente las capacidades humanas, sociales y económicas de la región. Deja en la sociedad una profunda huella cuyas consecuencias se cargan en la memoria colectiva y en la conciencia sicosocial de donde surgirán los traumas futuros. Habiendo llegado a niveles insostenibles, afortunadamente las muertes provocadas muestran una pequeña pero alentadora reducción en 2011 en Guatemala, Costa Rica, Nicaragua y Panamá y, una sorprendente baja a partir de marzo de 2012 en El Salvador. 


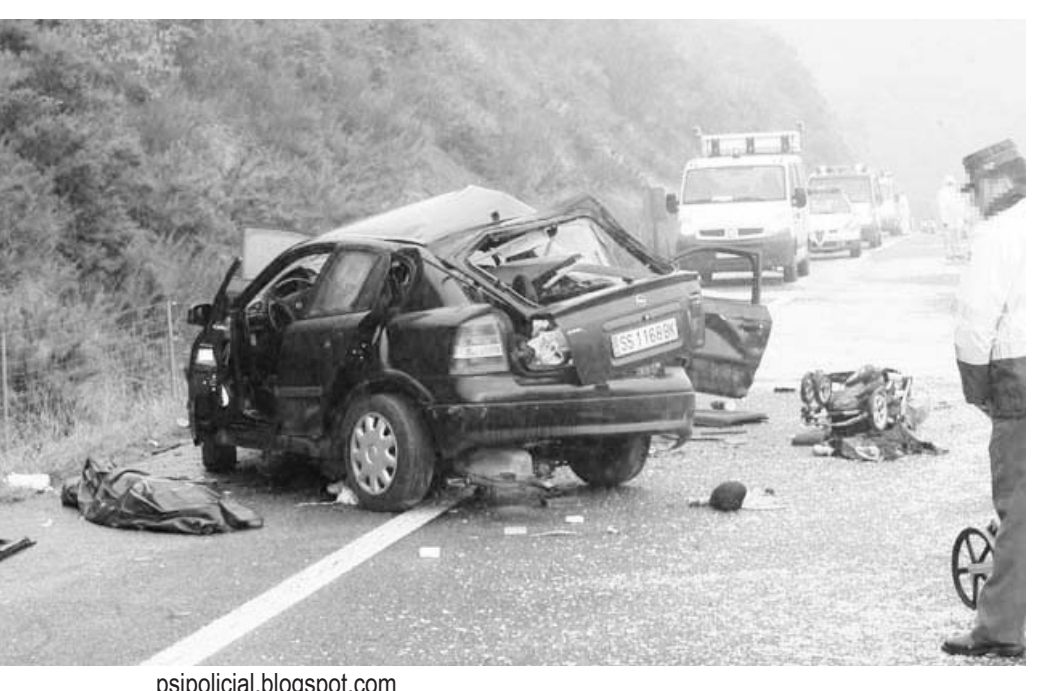

psipolicial.blogspot.com

La frecuencia de delitos graves cambia de manera sostenible y no ocasional, solo cuando se modifican las causas y circunstancias que lo originan. Esto es válido para la mayoría de las realidades nacionales, nuestra región no es la excepción. Lo observado el año pasado podría frustrarse en corto plazo si no se aprovechan las condiciones que permitirán quizás reducir en 2012 el 15\% (El Salvador aportará -13 puntos porcentuales) la reducción de muertes registradas en la Región en 2011 con respecto a 2010 quizás sea el punto de partida para evitar que tantas vidas se continúen perdiendo en esa escalada sorprendente que vivió la Región entre 2004 y 2010/2011.

Es una esperanza y una oportunidad para Centroamérica que requiere un nuevo compromiso o acuerdo de paz social sostenible fundado en la equidad, la tolerancia, el respeto y el diálogo incluyente como mecanismo fundamental para la solución de nuestras legítimas diferencias.

\section{Algunas fuentes bibliográficas:}

Bautista Lara, Francisco Javier, diversas publicaciones y estudios: www.franciscobautista.com

PNUD, Informe sobre Desarrollo Humano para América Central 2009 - 2010, "Abrir espacios a la seguridad ciudadana y el desarrollo humano", octubre 2009.

PNUD, "Seguridad Ciudadana 1998 - 2010, Nicaragua: Riesgos, Retos y Oportunidades, Nicaragua", agosto 2011.

Policía Nacional de Nicaragua, Anuarios Estadísticos 2005 - 2010, Nicaragua.

Sistema de Integración de Centroamérica, SICA, http:/ / www.sica.int/, julio 2012.

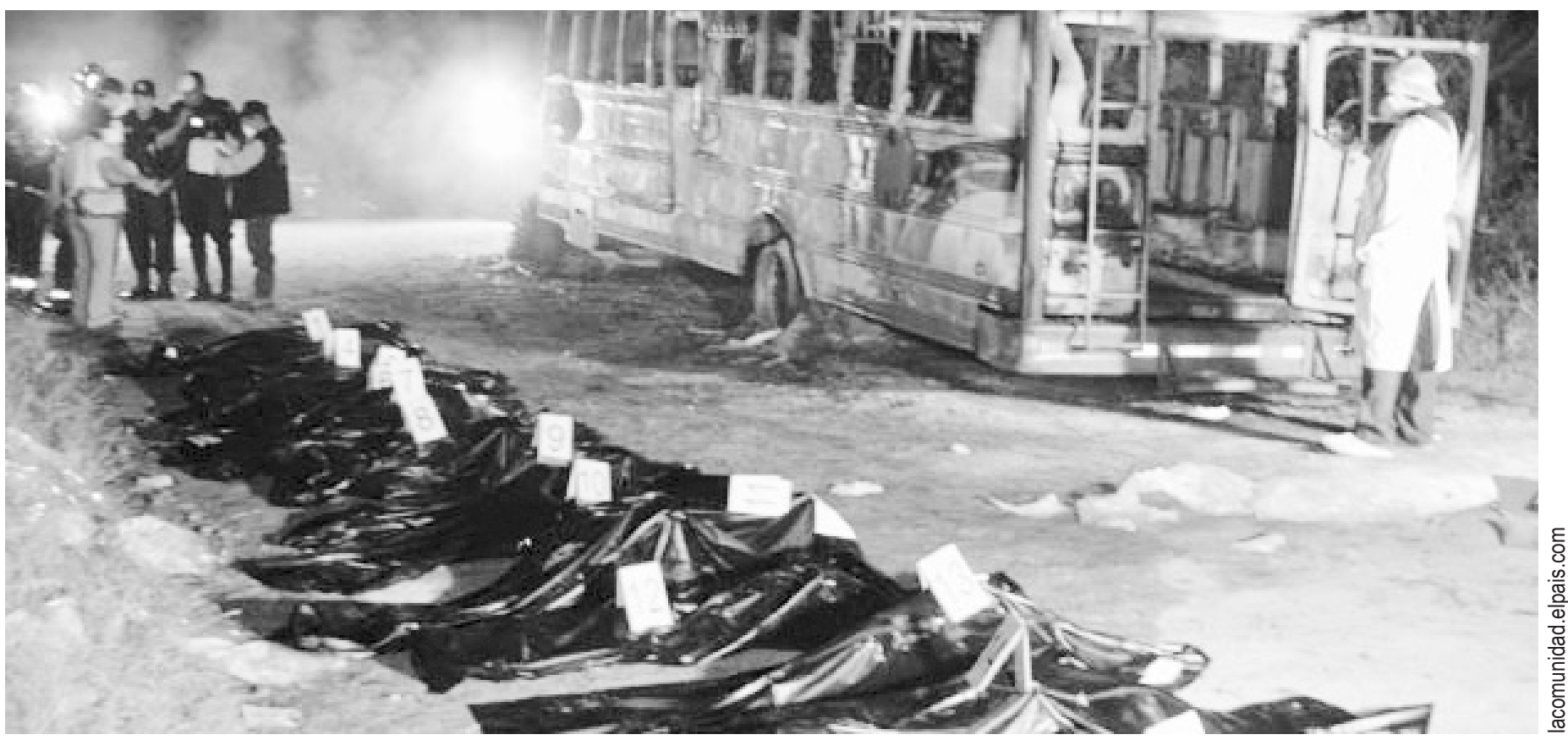

